\title{
César Vallejo: la prosa poética de algunos artículos periodísticos
}

\section{César Vallejo: the poetic prose of some newspaper articles}

Eduardo Huárag ${ }^{1}$

\section{Resumen:}

Estudio de algunas crónicas periodísticas (1924-1929) de César Vallejo que, luego de algunas modificaciones sustantivas, se convierten en prosa poética. Ciertamente, se produce una especie de vaso comunicante entre la crónica y el relato literario. Se aborda el mismo tema e incidente, y mientras en un caso prevalece la información periodística, en el otro modifica la expresión verbal y lo somete a las exigencias propias del relato literario. En este estudio se agrega, además, el análisis de dos textos de prosa poética que no tienen antecedentes en artículos periodísticos. Como se verá, se trata de un proceso de búsqueda en el que el poeta y narrador va definiendo su estilo, su prosa y su ideario ideológico.

Palabras clave: César Vallejo, prosa, poesía, periodismo, artículos periodísticos

1 Profesor ordinario-asociado de la Especialidad de Lingüística y Literatura de la Pontificia Universidad Católica del Perú.

Correspondencia (Corresponding author): ehuarag@pucp.pe

Código ORCID: 0000-0002-2553-0054 


\section{Abstract:}

Study of some journalistic chronicles (1924-1929) by César Vallejo that, after some substantive modifications, end up turning into poetic prose. Certainly, there is a sort of communicating vessel between the chronicle and the literary story. The same topic and incident are addressed, and while in one case journalistic information prevails, in the other the verbal expression is modified and subjected to the demands of the literary story. This study also adds the analysis of two poetic prose texts that have no precedent in journalistic articles. As will be seen, it is a search process in which the poet and narrator defines his style, his prose and his ideological ideology.

Key words: César Vallejo, prose, poetry, journalism, newspaper articles

\section{Introducción: premisas importantes}

La obra poética, como sostiene Heidegger (1979), es el resultado de un proceso de desinstrumentalización de la palabra. Agrego: el arte poética no se define solo con la elección de una palabra, sino con el conjunto de ellas que conforman un todo. La poética supone una combinatoria de palabras que, en el plano de la sugerencia, metaforiza y se adscribe a

324 la función estética.

En Vallejo, sus primeros escritos de poesía y relatos suponen una búsqueda en el que la intención comunicativa debe encontrar la palabra precisa. Hay que advertir que Vallejo, aun en sus escritos postmodernistas, no se reduce a un esteticismo, sino que emprende la búsqueda de un mensaje cuya significación se relacione con la condición humana. El poeta explora las posibilidades paradigmáticas y sintagmáticas en la 
conjunción de lo verbal con lo estético. Las emociones marcan picos de intensidad y los instantes en los que la palabra estalla. Al poeta no le queda más que transgredir para que lo verbal exprese el sentimiento que ahoga, que se agita en el interior del hombre. Vallejo pretende llegar a la esencia de la condición humana y también innovar la expresión verbal. Tal búsqueda no es simple.

Vallejo, singular en poesía, es también un narrador importante en el contexto de la literatura peruana. En el periodo de 1923 a 1938, Vallejo tuvo una intensa actividad periodística. Como anota Puccinelli (1987), Vallejo publica: “(...) en el diario "El Norte" de Trujillo (1923-30); en las revistas "Mundial" (1925-30) y "Variedades" (1926-30) y el diario "El Comercio" (1929-30) de Lima".

La doble búsqueda de Vallejo se refleja en el tratamiento de temas que solía abordar el modernismo (hechos insólitos y enigmáticos) y, a la vez, en la búsqueda de una expresión verbal que al dejar de lado las exquisiteces del modernismo, lo llevan a un estilo propio más cercano a la esencia del mensaje que desea trasmitir. Vallejo escribe varios artículos periodísticos sobre acontecimientos que pudieran tener cierto impacto en el público de la época, pero en esa búsqueda procede a una mutación del texto para convertirlo en relato, en prosa poética. Naturalmente, esto supone un proceso de resemantización. No un cambio de tema, sino un acto en el que la misma historia es sometida a un tratamiento de mayor condensación, de búsqueda de significaciones y sugerencia de mensajes trascendentes.

Al respecto, González Montes (2002) había advertido que Vallejo ya había ensayado ese procedimiento cuando publicó el artículo Abraham Valdelomar ha muerto y luego escribe Más allá de la vida y la muerte. Así, pues: 
En ambos casos el escritor expresa su congoja ante la pérdida de seres muy queridos para él: su amigo y mentor, el Conde de Lemos, y su madre. La diferencia reside en que el artículo nos muestra la reacción inmediata y periodística frente a una noticia que lo ha conmovido y de la que tiene que dar cuenta, aunque no lo quiera aceptar. En cambio, el cuento citado es una ficcionalización compleja y simbólica de un hecho que el escritor trata de superar a través de esta historia en gran parte fantástica e irreal. (pp. 44-45).

Por su parte, la exploración realizada por Puccinelli (1987) llega a distinguir:

(...) dos etapas o dos ciclos en el vasto conjunto de la escritura periodística de Vallejo. Una primera en que todavía se perciben los signos de su juvenil impronta modernista, etapa caracterizada por el regusto de la palabra, la búsqueda del término exquisito y refinado, le mot rare, por ciertos toques impresionistas; por una lírica introspectiva y una suerte de monólogo interior en el que aparece a ratos, curiosamente, la crónica mirándose a sí misma. (p. XII).

Como segundo ciclo, Puccinelli (1987) ubica los artículos periodísticos escritos desde 1925, cuando trabajaba en los periódicos iberoamericanos. El crítico señala que:

Para este nuevo destinatario va modelando la nueva escritura de sus crónicas y artículos que ingresan imperceptiblemente en el mismo espacio literario de sus "Poemas en prosa", y de sus "Poemas humanos", de los que constituyen un texto paralelo. Vemos cómo su juvenil preocupación por encontrar "le mot rare" es reemplazada por la búsqueda de "le mot juste", impactado por sus lecturas de Joseph Conrad. (p. XVI).

El corpus que he elegido está conformado por un conjunto de artículos publicados en Contra el secreto profesional, que han sido reunidos en Narrativa completa (1999). La edición de Ricardo Silva Santisteban reúne los textos que se consideran como prosa poética y también las crónicas periodísticas que se publicaron en revistas de la época. En 
este ensayo, lo que nos interesa advertir es de qué modo se produce la mutación de un artículo periodístico a relato de prosa poética. En ese trasvase, el autor procede a un tratamiento marcado por la abstracción, la metaforización y la condensación. El objetivo no es el análisis de todos los artículos periodísticos.

Como se apreciará, en el artículo periodístico lo que interesa es ofrecer la información que se ha convertido en noticia; en el relato (prosa poética) lo más importante es el tratamiento de la expresión verbal, estética, que no se queda en el gusto por la palabra, sino que condensa significaciones reflexivas acerca de la condición humana. Entre uno y otro existen aspectos similares. Y el escritor es consciente de que el tema periodístico es el punto de partida para la prosa poética.

De hecho, lo fundamental en la publicación de Contra el secreto profesional son los textos que luego aparecerán como prosa poética, resultado de la búsqueda de expresión de Vallejo. En este ensayo, he elegido dos artículos periodísticos: Un extraño proceso criminal, que da origen a Individuo y sociedad de la prosa poética; y Un atentado contra el regente Horty, que termina en la prosa poética como Teoría de la reputación. A ello he agregado, como análisis, relatos de Contra el secreto profesional que no tienen antecedentes en artículos periodísticos, como son: Ruido de pasos de un gran criminal y Vocación de la muerte.

\section{La necesaria definición ideológica}

Vallejo había revelado en Los heraldos negros (1919) su preocupación por el dolor humano y su actitud solidaria con los desposeídos. Por esa época, también le inquietaba el tema de los dobles, como lo demostró en la novela corta Fabla salvaje (1923). Parte de esas obsesiones -evidentes en la novela mencionada- estaban relacionadas con el misterio y los hechos 
inexplicables. Pero Vallejo no se limita a los temas propios del modernismo. Vallejo explora. En el poeta se produce una progresiva transformación en el estilo y en la opción ideológica. Según Oviedo (2001):

Su conversión ideológica es tan radical que durante casi todo ese periodo, aunque siguió escribiendo poesía, publicó muy poco de ello, pues estaba concentrado en tareas para él más urgentes entonces: el periodismo y la literatura de combate ideológico a favor de la revolución. (p. 337).

Es importante agregar que en ese periodo se produce una constante búsqueda de estilos, modalidades narrativas y formas poéticas. Ello explica que algunos de sus textos sean difíciles de clasificar. Pueden ser crónicas, ensayos o prosa poética. Aunque su preferencia es la poesía, Vallejo no deja de incursionar en el relato. Y como es un periodo de exploración, sus escritos muestran esos puentes, esos caminos en los que se juntan los afanes de relatar con la marca indiscutible de poetizar.

Chang-Rodríguez (1994) dice: "Vallejo con frecuencia transforma los textos que traslada a crónicas o poemas, expandiéndolos o condensándolos” (p. 348). Esa apreciación es cierta, aunque él lo deja como una afirmación genérica. En este ensayo, me interesa ahondar en las similitudes y diferencias que encontramos entre el artículo periodístico y el relato en prosa poética. Por entonces, al poeta le llaman la atención

328 los hechos y noticias que suceden en Europa, especialmente los acontecimientos policiales, pero también las noticias culturales y las que proceden de los debates ideológicos o políticos. Y también está definiendo su función social como escritor y, por lo mismo, su opción política. Tiempo después concretará su filiación al Partido Comunista Francés. Es necesario saber que Vallejo, aun afiliado, defiende la independencia del trabajo intelectual. El escritor no puede someterse a los dictámenes de los partidos políticos. 


\section{Análisis de un artículo con tema policial}

Un extraño proceso criminal es un artículo que apareció en la revista Mundial (26 de agosto de 1927). Los epígrafes que anuncian el artículo son: Las audacias de un delincuente y la sicología policial. Los acusados y sus dobles. Asombroso parecido entre Guyot y Mhilad (Vallejo, 1999, p. 248). Al inicio, se describe al personaje protagónico, un tal Gastón Guyot, acusado de haber estrangulado o quemado a su amante Malou.

El homicida, luego del incidente, se paseaba por las calles sin ocultarse de la policía. Un hecho paradójico: lo lógica nos dice que el perseguido debería esconderse, pero este ciudadano hace exactamente lo contrario. Según el cronista: "La policía no podía encontrarle, justamente, porque él no se había escondido" (p. 249). Se dice que Guyot "entraba y salía de su casa, almorzaba con amigos en los grandes boulevares (...) y la policía seguía ignorando totalmente sus trazas y su pista” (p. 249).

Destaquemos que en un acto de audacia, Guyot enviaba cartas a la policía. En la primera carta dice: "Señores (...) no hay tal crimen (...). Esa niña se ha suicidado. De ustedes, muy atentamente, un hombre honrado" (p. 249). En otra, dice: "Veo que se está persiguiendo a M. Guyot, como posible matador de Malou. No hay tal. Soy yo quien ha estrangulado a esa muchacha, un chauffer" (p. 249). Y en una tercera carta, dice: "Se me persigue, en verdad, injustamente. Confieso ante Dios y los hombres que soy inocente. ¿Qué podré hacer para probarlo? Si no lo logro, me arrojaré al Sena” (p. 249). Al final, el cronista concluye que para no ser capturado por la policía no hay que ocultarse: "Tal es el aporte de Guyot a la sicología policial” (p. 249).

Guyot fue sentenciado por asesinato premeditado. Pero el hecho más importante se produce en el sexto párrafo. Y es 
que el acusado Guyot, al dirigir una mirada al tribunal se sorprendió de que el sustituto del presidente del tribunal tuviera un extraordinario parecido a él: "El procesado vio su doble y algo debió cambiar en su reino interior" (p. 250). Un hecho inesperado. Tal presencia le perturba: "La presencia de Mhilad le hacía, sin duda, un daño creciente, influyendo funestamente en la marcha de su espíritu" (p. 251). Tan desconcertado estaba que, en la segunda audiencia, el acusado era: “(...) un guiñapo de hombre, un deshecho, un culpable irremediablemente perdido” (p. 251).

La conclusión a la que llega el cronista es que: "El doble juega entonces el múltiple rol de un juez severo, de un testigo terrible, de un acusador implacable. Guyot es, en síntesis, un hombre trascendental" (p. 251).

\subsection{La mutación de la crónica periodística a la prosa poé- tica}

Ahora bien, en Narrativa completa (1999) se distingue la crónica periodística de los textos en prosa poética. El incidente del texto analizado como crónica periodística fue sometido a una transformación y apareció en prosa poética como Individuo y sociedad. En la versión de la prosa poética se omitieron los cinco primeros párrafos de la crónica. No le interesaban, en esa oportunidad, los detalles de la noticia periodística.

330 Como hemos visto, el artículo periodístico incluido en Contra el secreto profesional se centra en el extrańo y misterioso parecido del acusado con el señor Mhilad, presidente sustituto en el tribunal: "Un doble absolutamente idéntico. El asesino vio a su doble y algo debió acontecer en su conciencia" (Vallejo, 1999, p. 227).

En el texto Individuo y sociedad se repiten las mismas preguntas que hizo el tribunal al acusado respecto a su gusto 
por las mujeres. Pero hay diferencias sutiles. El discurso de la prosa poética es más preciso y condensado que la crónica periodística: "La presencia de Milad (sic) le hacía un daño consciente, influyendo funestamente en la marcha de su espíritu y del juicio. Al final de la primera audiencia, sacó su pañuelo y se puso a llorar" (p. 227). Nótese que se emplea la misma frase discursiva para resaltar el efecto del doble. Se dice que el condenado era "un guińapo de hombre, un deshecho, un culpable irremediablemente perdido. Casi no ha hablado ya" (p. 228). Luego concluye de modo original y reflexivo: "A tal punto es social y solidaria la conciencia individual" (p. 228).

El texto poético puede estar endeudado con la información que proporciona la crónica periodística, pero el tratamiento es distinto. Por eso se da el final reflexivo. Un final en el que lo social y lo individual interactúan y dependen uno del otro. $\mathrm{El}$ individuo puede pretender ser totalmente independiente, pero basta ser consciente de lo que nos rodea para saber que nuestra individualidad está inevitablemente ligada al ser social. Por tanto, no hay una contraposición entre individuo y sociedad. Uno de ellos (lo social) contiene al otro.

Lo extraño, lo misterioso es también parte de la vida humana. La presencia de un doble es un hecho desconcertante y tiene una repercusión inesperada. El protagonista, acusado de homicidio, que hasta ese momento no parecía tener cargo de culpa, ante el doble, se ve a sí mismo. Es el principio del espejo. El personaje que está ante él, en el tribunal, parece ser la proyección de sí mismo. De esta manera, desaparece el desenfado y se impone la culpabilidad. $Y$ es esa culpa la que convierte al individuo en guiñapo humano. Tal culpabilidad no la había sentido antes, aparece por estar ante la proyección de su yo, de su conciencia interior. Por eso: "Al leerse el veredicto de muerte, estuvo hundido en su banco, la cabeza sumersa entre las manos, insensible, frío, como una piedra" 
(p. 228). Y al salir del tribunal, su mirada final era para Mhilad, su doble, el sustituto (p. 228).

Pero, ¿cuál es el propósito de presentar un misterioso doble que se yergue como conciencia acusadora? Pareciera que responde a la discusión sobre la dicotomía individuo-sociedad. Dos aspectos que parecen distintos pero que, en cierto modo, son complementarios. No es posible entender la individualidad, sin aceptar que el individuo es parte de la realidad social; y lo social no es sino un conjunto de individualidades. La dicotomía parece haber interesado a los modernistas, quizá más de lo debido. Para Gatgens (2011), los modernistas se focalizaban en el individuo y no el suceso en sí. Entonces: “(...) al enfocar lo personal se deja de lado lo general: el hecho, y se escribe, se mira, se lee desde una perspectiva más particular, tratando de comprender al ser humano, al que le suceden las cosas que le suceden" (p. 97).

La dicotomía la definirá Vallejo tiempo después, con la explicación marxista, para quienes el individuo se define en su ser social. Es importante que lo que le preocupa a Vallejo es el proceso de transformación del hombre. Por un lado, se destaca la importancia de la individualidad y la libertad; pero a la vez no se concibe al individuo ajeno a la sociedad. De esta manera se puede entender dos frases insertas como paradoja: "A tal punto es social y solidaria la conciencia individual. (...) A tal punto el individuo es libre e independiente de la sociedad" (Vallejo, 1999, p. 228).

Neale-Silva (1987) considera que el acto de la sustitución propone "la idea de que habrá algún día un ajusticiamiento y que el viejo sistema habrá de desaparecer” (p. 202). Planteamiento que no nos convence, porque el relato presenta una extraña similitud del ajusticiado con el ajusticiador. ¿Quiere decir eso que el nuevo sistema será justiciero, pero idéntico al transgresor que condenamos? Preferimos creer que un hecho 
externo, inexplicable, puede desconcertar al punto de transformar la interioridad del hombre. $Y$ tal desconcierto es de tal naturaleza que instala la culpabilidad.

Estamos ante un aspecto complejo de la naturaleza humana. Vallejo se propone develar esa verdad. Desocultar la verdad, al estilo de Heidegger. Develar lo que subyace, lo extraño, lo misterioso, lo inexplicable. $\mathrm{Y}$, sin embargo, todo es parte de la condición humana. Lo interesante es que, como relato, termina despertando el interés del lector acerca de lo extraño y enigmático. Interrogantes que siempre estarán presentes en el ser humano.

\section{El artículo periodístico sobre un atentado y su muta- ción}

Otra crónica periodística que nos interesa es la que Vallejo titula Un atentado contra el regente Horty, escrito en Budapest, en 1928 y publicado en Mundial en 1929. Esta crónica apareció después con el título Teoría de la reputación. Los textos son idénticos, salvo un párrafo que se ha omitido.

El relato se inicia con una referencia que había estado en la taberna Sztaron, cuyo gerente es Ossag Muchay: "Hablamos de las supersticiones del Asia Menor, de las salobres ciencias de aprehensión, de las hechicerías" (Vallejo, 1999, p. 255). Pero entonces aparece un texto explicativo que ha sido omitido en la versión reescrita. En la crónica se dice:

Ossag Muchay es manifiestamente otomano. Al charlar de tan amable tema de fe, he estado de ello seguro con suavidad y abundancia. Ossag Muchay es turco. Su palabra, sin duda, no lo quiere, pues suena a violoncelo juglaresco, a esa nacida condición sonora, labrado en dyramátev aserrado, en la que el ardiente país de Bohemia echa, con voz escurridiza, la buena ventura. Pero, en pro y en contra, Ossag Muchay es turco. (p. 255). 
Es este, pues, el párrafo omitido. ¿Por qué se procede a la omisión del párrafo? Quizá el escritor consideró que la digresión no era tan relevante como para incluirlo en la otra versión. O quizá, siendo interesante, se desvía del tema. Es curioso observar que aunque en este párrafo se ha procedido a un tratamiento que se aparta del lenguaje cotidiano en un afán de desinstrumentalizar lo verbal, el escritor no lo incluye en la versión posterior.

Después de despedirse de Muchay, el cronista observa que el comisario le pregunta al detenido por su nombre. El hombre le responde: "Yo no tengo nombre" (p. 230). El enigma o misterio se mantiene tal cual en Teoría de la reputación. Se dice que nadie sabe su nombre, ni allí, ni en la ciudad donde residía: Loeben. El cronista regresa, entonces, a la taberna y le comenta el incidente a Muchay. Este no parece sorprenderse: "Ese individuo carece, en verdad, de nombre. Soy yo quien guarda su nombre. ¿Quiere usted conocerlo?" (p. 230). El cronista se muestra desconcertado. Parecía un hecho absurdo, insólito. ¿Parte de un enigma? ¿Cómo puede ser que un individuo se apropie de la identidad de otro individuo? Muchay tiene una explicación: "Aquel hombre perdió su nombre y él mismo, aunque quisiera darlo, no puede ya saberlo. Le es absolutamente imposible, en tanto no tenga en su poder la firma que usted está viendo aquî" (p. 230).

La explicación parece una burla. El cronista sostiene que si alguna vez hizo una firma, podría hacer otra. Pero entonces surge la explicación del nombre y la identidad de la persona. Es decir, esa mágica y extraña relación entre un nombre y la persona. Muchay explica su creencia, su verdad: "el nombre verdadero de muchas personas se ignora. Esta es la causa por la cual, en lugar de apresar al obrero de Loeben, no se ha apresado al patrón de la fábrica donde éste trabaja" (p. 231). 
Por lo que se puede apreciar, Vallejo ha tomado el motivo del Atentado contra el regente Horty para luego plantear un tema de reflexión: el de la relación del nombre de la persona con el sujeto real que no puede reconocerse porque ha perdido el nombre. Este tema parece haber estado entre las motivaciones principales de la narrativa fantástica. Recordemos el cuento La protección del libro de Willoughby-Meade. Relato que Borges, Ocampo y Casares (1971) consignan en Antología de la literatura fantástica (pp. 429-430). En ese relato breve, el protagonista es el literato Wu que aguardaba la venganza de un mago a quien había insultado. En la noche, apareció un guerrero que lo amenazó con su lanza. Wu lo derribó con su libro. Al inclinarse, Wu descubrió que el mago no era más que una figura de papel. Aparecen dos pequeños espíritus a los que también derribó y terminaron siendo figuras de papel. A media noche llamó a la puerta una mujer que reclamaba por su marido y sus hijos, los cuales habían sido encerrados en un libro. Wu negó tenerlos y la mujer insistía en que sus almas estaban en esas figuras.

Volviendo al relato: ¿Cuál es el límite entre los hechos de la realidad y la interpretación de lo acontecido? Vallejo se desconcierta porque, según la lógica, el nombre no es más que una simple referencia, como las figuras de papel del relato fantástico. La figura encierra el alma de la persona que representa. Cuando el literato Wu guardó la figura de sus agresores en el libro, guardó el alma de los personajes. Lo mismo hizo el señor Muchay, quien guardó el nombre del apresado: "Ese individuo carece, en verdad, de nombre. Soy yo quien guarda su nombre" (Vallejo, 1999, p. 230).

Los personajes, el cronista y Muchay parecen una contraposición de identidades. El cronista hace esfuerzos por entender el razonamiento de Muchay, que ha atrapado el nombre, lo esencial del individuo. Muchay ofrece una argumentación que se sale de la lógica, como se alejan el poeta y el filósofo. 
Pareciera que se revela el otro lado de la identidad del poeta, es decir, de Vallejo. Por eso, Neale-Silva (1987) considera que: "El sentido fundamental del relato está implícito en la estructura anímica de sus dos personajes principales, quienes resultan ser las dos caras de una misma entidad humana. No creemos justificado, por lo tanto, concebir las figuras centrales como actantes opuestos" (p. 253).

Esto explicaría también ese final desconcertante: "Y me quedé Vallejo ante Muchay" (Vallejo, 1999, p. 231). Y es que Vallejo discurre dialécticamente entre él, como poeta, y el entrevistado que resulta ser un ciudadano con ideas originales. La frase final insinúa la fusión de tales personajes con lo que volvemos a encontrarnos con el principio dialéctico de la unidad de contrarios.

\section{Un relato sin referente periodístico}

Con Ruido de pasos de un gran criminal nos encontramos con un relato que aparece como prosa poética y sin referentes periodísticos. Tiene tres párrafos: los dos primeros empiezan con la frase: "Cuando apagaron la luz...", lo que hace suponer la percepción de lo que acontece en la oscuridad. Se reflexiona considerando la dicotomía luz/oscuridad. Contradictoriamente, cuando se produce la oscuridad, las cosas parecen tener vida. Por eso, en el primer párrafo, se dice que:

Las cosas reanudaron en la oscuridad sus labores, en el punto donde se habían detenido: en un rostro, los ojos bajaron a las conchas nasales y allí hicieron inventario de ciertos valores ópticos extraviados, llevándolos en seguida, a la escama de un pez llamó imperiosamente una escama naval, tres gotas de lluvia paralelas detuviéronse a la altura de un umbral, a esperar a otra que no se sabe por qué se había retardado. (Vallejo, 1999, p. 232).

Nótese que, en este texto, que no aparece vinculado a ninguna crónica periodística, el poeta se concentra más en la 
poetización y la sintagmática que violenta la norma para metaforizar.

Más adelante, en el mismo párrafo mencionado, se repite la frase para agregar otras referencias que suponen dinamismo en oposición a la oscuridad: "Las cosas, a la sombra, reanudaron sus labores, animadas de libre alegría y se conducían como personas en un banquete de alta etiqueta, en que de súbito se apagasen las luces y se quedase todo en tinieblas" (p. 232). El misterio y el afán de poetizar son evidentes. En el segundo párrafo se sigue reflexionando sobre el sentido de la oscuridad. Y es que lo oscuro no es lo negro. La oscuridad puede replantear un nuevo orden:

Cuando apagaron la luz, realizose una mejor distribución de hitos y de marcos en el mundo. Cada ritmo fue a su música, cada fiel de balanza se movió lo menos que puede moverse un destino, esto es, hasta así adquirir presencia absoluta. En general, se produjo un precioso juego de liberación y de justeza entre las cosas. Yo las veía y me puse contento, puesto que en mí también corcoveaba la gracia de la sombra numeral. (p. 232).

Pareciera que en medio de la oscuridad se definen mejor las cosas. Los elementos buscan su complemento. En el vaivén, los elementos buscan el punto justo. Pero la oscuridad no es permanente. Llega la luz y se acaba el sueño:

No sé quién hizo de nuevo la luz. El mundo volvió a agazaparse en sus raídas pieles: la amarilla del domingo, la ceniza del lunes, la húmeda del martes, la juiciosa del miércoles, la zapa del jueves, la triste del viernes, la haraposa del sábado. El mundo volvió a aparecer así, quieto, dormido o haciéndose el dormido. (p. 232).

Es la descripción de un despertar a la luz del mundo. Una vida cotidiana en la que cada día tiene un valor. Esto deja la sensación de que todos los anhelos de justeza y liberación se produjeron en la noche, en esa oscuridad que parece crear su propio mundo. El texto no desliga su sentido del título. En el título 
se alude a "Ruidos de pasos de una gran criminal", y el texto pareciera (en lenguaje fílmico) la subjetiva de un sujeto que avanza en la oscuridad. En todo caso, más allá del referente, lo que queda es una descripción dicotómica: luz/oscuridad y un conjunto de reflexiones que esperan ser metafóricas.

\section{Un relato acerca del dilema de lo sacro y lo mundano, y la función mesiánica}

Un texto significativo es el que titula Vocación de la muerte. En este caso, hay que señalar que aparece como prosa poética, mas no tiene antecedente o tratamiento periodístico. La trama narrativa alude a María y a su hijo. Se trata de una familia judía y de un joven que no parecía tener interés por los quehaceres de la vida cotidiana. Llama la atención que en la historia, ubicada en el antiguo pueblo hebreo, se incluyen elementos como aquello de que uno de los doctores leía un libro de Lenin, y otro dice: "Me llaman por teléfono. Volveré." (Vallejo, 1999, p. 242). De esta manera, con un simple dato del referente, Vallejo quiere ubicar el tema como parte de las inquietudes y reflexiones del hombre contemporáneo.

Los hechos se producen en Nazareth cuando el hijo de María ha llegado a los 30 años, sin oficio, “ (...) y no tenía ninguna vocación ni orientación concreta” (p. 242). Es evidente que la trama inevitablemente se vincula al relato bíblico en el que se menciona que Jesús tuvo como madre a María. Como se 338 sabe, por la Biblia, María tuvo ese hijo luego de una anunciación. Lo que significa que fue designada para tal fin. De esa manera, Jesús se presentará no como un ser humano más, sino como un ser de procedencia divina.

En un encuentro familiar, Susana intentó hablarle: "Pero el hijo de María no respondió: justamente, en ese instante, acababa de morir" (p. 243). Luego, el escritor hace mención 
de un extrańo suceso en el que se pone en evidencia la vida trascendente y la revelación del Mesías:

Hillel (...) tuvo una repentina exaltación visionaria y, dirigiéndose al joven de gran hermosura, que iba con ellos, le dijo: (...) ¡Ya eres, señor, el Hijo del Hombre! ¡En este momento, Señor, empiezas a ser el hijo del hombre! En este momento, señor, empiezas a ser el Mesías, anunciado por Daniel y esperado por la humanidad durante siglos. (p. 243).

Se había producido la revelación, la identificación del designado. Era una vida diferente. Frente a la muerte o el desapego de la realidad y la vida cotidiana, aparecía un nuevo personaje, el esperado Mesías. Y por eso, el personaje aludido dijo: "Yo soy el Hijo del Hombre, el enviado de mi Padre -respondió el joven de las maneras suaves y la gran hermosura, como si acabase de tener una revelación por espacio de treinta años esperada" (p. 243).

Era como si toda la vida hubiese estado esperando el momento de la revelación y que le reconociesen como el designado. Vallejo ha sabido recrear un episodio de la historia religiosa e insertarla en los tiempos contemporáneos. Es decir, encontrar lo universal del episodio religioso. Así pues, el enviado no fue reconocido, porque los humanos se dejaban atrapar por la cotidianeidad y olvidaban lo trascedente.

Pese a ello, el que se haya escrito sobre un tema religioso nos parece relevante. Neale-Silva (1987) considera que "El Cristo de 'Vocación' no es el Cristo de un hombre devoto, sino el Cristo de un artista y pensador que se halla en vísperas de una gran conversión espiritual" (p. 233). Para Vallejo, se trata de una opción ideológica que debiera ofrecer una explicación de la realidad y la vida misma. Pero, como muchos temas que aborda Vallejo, el enfoque y la interpretación plantean dilemas. La transformación del hombre en Mesías es un acto decisivo. El hombre asume otro rol ante el pueblo. Por eso, Neale-Silva dice 
que, el: “(...) ingrediente más poético y más original de todo el cuento es la transformación de Jesús. Desaparece el hombre de la historia y surge en su lugar el Mesías prometido" (p. 233). Jesús dejaría de ser humano para asumirse como ser sagrado.

El tema está planteado desde la perspectiva de un pensador que elogia la transformación y la revelación religiosa. Vallejo propone una necesaria reflexión sobre el tema. Por esos años, en Vallejo todavía existía una lucha interna entre su filiación católica y el planteamiento marxista. Mendoza Ripaz (2020) considera que:

(...) la alegoría Cristo - Lenin nos remite a muerte y sacrificio. La muerte de Cristo fue un sacrificio para conseguir la redención y resurrección de la humanidad, por la conversión a través del bautismo que implica morir a la vida de pecado y nacer a una nueva vida en Cristo, y la muerte de Lenin fue el sacrificio por la revolución. Entonces la vocación de la muerte es el sacrificio por amor a los ideales.

Décadas después, un cineasta de prestigio como Martin Scorsese realizó La última tentación de Cristo, filme en el que se observa a un Jesús que no entiende que era el esperado Mesías. Jesús pretendía ser un humano como los demás. Su madre, que sabía de las profecías, le inculca a Jesús la idea de que él era el esperado. Jesús acepta su destino de Mesías y espera que en el momento final de su vida se produzca el milagro. El hecho extraordinario que él esperaba no se produce

340 y por eso sus palabras conmovedoras: "Padre, por qué me has abandonado". Entonces, desde esa perspectiva, el debate está abierto. Se trata de un tema de inquietud universal.

En suma, en el periodo de 1924 a 1928, Vallejo explora temas sobre la compleja realidad humana. Su estilo y tratamiento suponen una necesaria actitud reflexiva ante lo insólito o extraordinario. En cada artículo se pueden observar algunos vínculos (por el tema o por el estilo) con el posmodernismo 
y también se aprecian sus inquietudes por la expresión vanguardista y el enfoque dialéctico para la interpretación de la realidad. En su prosa poética, Vallejo pone en evidencia su estilo condensado y la búsqueda trascendente más allá de los hechos incidentales. En una entrevista a la que hace referencia Chang-Rodríguez (1994), se menciona que Vallejo concedió una entrevista y en una de sus respuestas dijo:

La precisión me interesa hasta la obsesión. Si usted me pregunta cuál es mi mayor aspiración en estos momentos no podría decirle más que esto: la eliminación de toda palabra de existencia accesoria, la expresión pura, que hoy mejor que nunca habría que buscarla en los sustantivos y en los verbos. (p. 348).

En muchos casos, el artículo periodístico es el puente que conduce al relato literario. No se queda en lo incidental. Su interés prioritario es profundizar en los rasgos que caracterizan a la naturaleza humana, pero también en la construcción de un texto que se nos presenta como prosa poética.

\section{Conclusiones}

El estudio de la prosa poética de Vallejo en los artículos periodísticos aquí reseñados me permite formular las siguientes conclusiones:

1) Vallejo explora las posibilidades expresivas e intenta la transposición de un artículo periodístico a un relato literario que se conoce como prosa poética. Naturalmente, esta transposición requiere del autor un tratamiento, una resemantización y toda la connotación que está más allá de lo meramente denotativo.

2) El tema de los dobles vinculado a un homicidio merece especial atención del escritor. El relato policial ciertamente trata de un hecho insólito; pero el tratamiento derivará en una situación que afecta al inculpado de modo que 
sentirá que "su otro" le acusa y no podrá superar ese estado de afectación. El tema queda como un hecho insólito y enigmático, como muchos manifiestos de la naturaleza humana.

3) Lo que ocurre en Individuo y sociedad puede ser una pauta del procedimiento que emplea Vallejo en la transposición. El escritor descarta cinco párrafos que para efectos literarios se juzgan como no significativos. Es decir, ha optado por la condensación de acontecimientos para buscar lo trascedente y lo que se puede decir acerca de la condición humana. De ese modo, la culpabilidad es una consecuencia que deriva de la constatación del doble y que incide en una "fractura" de la interioridad. El tema de los dobles fue un tópico recurrente en la narrativa modernista y postmodernista. En el caso de Vallejo, el tema le permite dejar en sus lectores las reflexiones acerca de lo enigmático y lo inexplicable.

4) En Teoría de la reputación se aprecia la mágica proyección del nombre en la identidad de la persona. De manera que toda sustitución podría tener efectos devastadores, como alegóricamente y de manera semejante se refiere en el relato chino, de autoría anónima, titulado La protección del libro. Hechos en los que lo fantástico es parte inevitable de la realidad humana.

5) En el relato Vocación de la muerte se refiere un tema que en términos generales no es ajeno a las inquietudes del escritor: la religiosidad. En este caso, hace alusión a Jesús como predestinado. Lo que significa que dejaría de ser humano para considerarse un ser sagrado; el momento más crítico y discutible termina cuando acepta morir (y no puede evitar la muerte del hombre) y luego reaparece como transfigurado. 
6) Finalmente, Vallejo es consciente de que está procediendo a una transposición del discurso periodístico a la prosa literaria. Sabe que, en el segundo caso, debe descartar la información incidental o accesoria. Un cambio paradigmático que influirá en la expresión verbal.

El presente artículo espera contribuir a los estudios literarios que se esmeran en los ejes temáticos de una obra o el conjunto de publicaciones de un autor y se interesan poco de las mutaciones discursivas que son parte fundamental en la comprensión de la palabra exacta y precisa (le mot juste) de un escritor. Aspecto relevante en el estudio de Vallejo.

Recibido: 15 de enero del 2021

Aprobado: 18 de abril del 2021

\section{Referencias bibliográficas}

Abril, X.

(1963)

César Vallejo o la teoría poética. Madrid: Taurus.

Ballón Aguirre, E.

(1985) Poetología y escritura. México, D.F.: Ediciones de la UNAM.

Chang-Rodríguez, E.

(1994) La superación del modernismo en las crónicas de César Vallejo. En J. Cornejo Polar y C. López Degregori (Eds.). Vallejo. Su tiempo y su obra. Actas del Coloquio Internacional (t. 1, pp. 345-351). Lima: Universidad de Lima.

Gatgens, J.

(2011) Vallejo poeta, Vallejo periodista 'dos espiritus' en el mismo escritor". Revista Ensayos Pedagógicos, 6(1), 97. 
González Montes, A.

(2002) Escalas hacia la modernización narrativa. Lima: Fondo Editorial de la UNMSM.

Heidegger, $M$.

(1979) Sendas perdidas. Buenos Aires: Editorial Losada.

Mendoza Ripaz, R.

(2020) Visión de la muerte en la prosa de César Vallejo (Tesis para optar el grado de magíster en literatura peruana y latinoamericana). Universidad Nacional Mayor de San Marcos, Facultad de Letras y Ciencias Humanas, Unidad de Posgrado, Lima.https://cybertesis.unmsm. edu.pe/handle/20.500.12672/5824?show=full

Neale-Silva, E.

(1987)

César Vallejo, cuentista. Escrutinio de un múltiple intento de innovación. Barcelona: Eds. Salvat.

Oviedo, J. M.

(2001)

Historia de la literatura hispanoamericana (t. 3). Madrid: Alianza Editorial.

Puccinelli, J.

Desde Europa: crónicas y artículos (1923-1938). Lima: Eds. Fuente de Cultura Peruana.

Vallejo, C.

Narrativa completa. Ed. de Ricardo Silva-Santisteban y Cecilia Moreano. Lima: Pontificia Universidad Católica del Perú.

Willoughby-Meade, G.

(1971) La protección del libro. Cuento chino de autor anónimo. En J. L. Borges, S. Ocampo y B. Casares (Comps.), Antología de la literatura fantástica (pp. 429-430). Buenos Aires: Ed. Sudamericana. 